\title{
UM OLHAR SOBRE A CULTURA DA DESIGUALDA- DE ENTRE HOMENS E MULHERES
}

\section{A LOOK AT THE CULTURE OF INEQUALITY BE- TWEEN MEN AND WOMEN}

Genivaldo Bezerra Cavalcanti ${ }^{1}$ Luiz Carlos da Silva ${ }^{2}$

Resumo: O presente estudo ob- bibliográfica. A diferença entre jetiva resgatar a trajetória histó- homens e mulheres demonstra rica do tratamento dispensado às o machismo como atitude de mulheres, sob o prisma das prin- prepotência dos homens relaticipais condicionantes, tais como vamente às mulheres. Ideologia relações econômicas, legislação, essa que descende principalmencrenças, valores, costumes e a te do seio familiar, ou seja, esse cultura em geral, que criaram preconceito é uma bagagem culuma superestrutura ideológica de tural, grande fator para a formadiscriminação do universo femi- ção da vida social do indivíduo nino. A abordagem da temática fortemente enraizada na cultura desenvolveu-se de forma teóri- nordestina em especial em Perca, com aplicação do método de nambuco. A questão norteadora abordagem indutivo e dedutivo, busca verificar se a mulher pere do procedimento da pesquisa nambucana, ao longo do tempo,

1 Especialista em Antropologia pela FACULESTE

2 Especialista em Ensino de História pela FAFICA

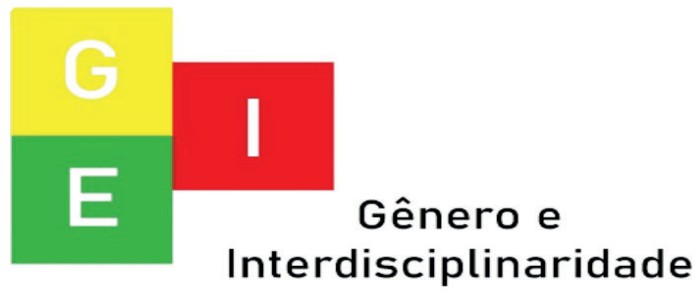


ISSN: 2675-7451

Vol. 02 - n 03 - ano 2021

Editora Acadêmica Periodicojs

conseguiu ocupar um espaço de igual importância e valor com os homens? Em hipótese houve avanços, mas a igualdade entre os gêneros ainda está longe de ser atingido. Esse estudo tem por objetivo compreender que o machismo continua existindo, além de discutir os conceitos de gênero, analisa as raízes, crenças, ideias e valores no meio familiar e também identifica os direitos e a identidade da mulher, que apesar de existir, é negado na sociedade. A conclusão é de que as conquistas do ponto de vista legal e social ampliaram a cidadania e emancipação das mulheres, reconhecendo-as como cidadãs plenas de direitos, contudo o desafio é materializar a igualdade de gênero, com respeito às diferenças, e superar a ideologia que naturalizou a submissão das mulheres no decorrer da história.

\section{Palavras-chave: Desigualdade} entre homens e mulheres. Machismo. Discriminação. Sociedade

\begin{abstract}
This study aims to rescue the historical trajectory of the treatment given to women, under the prism of the main conditions, such as economic relations, legislation, beliefs, values, customs and culture in general, which created an ideological superstructure of discrimination against the female universe. The thematic approach was developed in a theoretical way, with the application of the inductive and deductive approach method, and the bibliographical research procedure. The difference between men and women demonstrates machismo as a prepotency attitude of men towards women. This ideology descends mainly from the family, that is, this prejudice
\end{abstract}

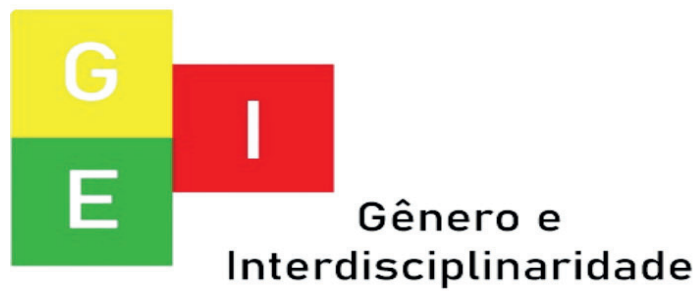


ISSN: $2675-7451$

Vol. 02 - n 03 - ano 2021

Editora Acadêmica Periodicojs

is a cultural baggage, a great factor in the formation of the individual's social life, strongly rooted in the northeastern culture, especially in Pernambuco. The guiding question seeks to verify whether women from Pernambuco, over time, managed to occupy a space of equal importance and value with men? Hypothetically, progress has been made, but gender equality is still far from being achieved. This study aims to understand that machismo continues to exist, in addition to discussing the concepts of gender, it analyzes the roots, beliefs, ideas and values in the family environment and also identifies the rights and identity of women, who despite existing, are denied in society. The conclusion is that the achievements from the legal and social point of view have expanded the citizenship and emancipation of women, recog- nizing them as citizens with full rights, however the challenge is to materialize gender equality, respecting differences, and overcoming ideology that naturalized the submission of women throughout history.

Keywords: Inequality between men and women. Chauvinism. Discrimination. Society.

\section{INTRODUÇÃO}

Ao longo da história, o debate da diferença entre os sexos desenvolveu-se principalmente entre duas perspectivas: a essencialista e a culturalista. O discurso essencialista exalta a "diferença sexual" e defende a existência de uma "essência feminina". Tornando psicológicas ou pessoais as constatações sociológicas e culturais historicamente produzidas, realizam afirmações univer-

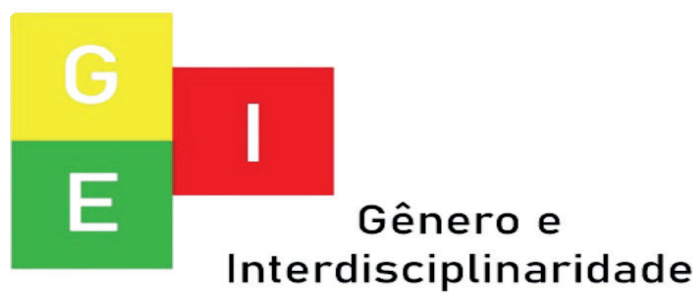


ISSN: 2675-7451

Vol. 02 - n 03 - ano 2021

Editora Acadêmica Periodicojs

salistas que aprisionam a feminilidade em modelos estruturados, ainda que ideologicamente valorizados (mulher como mãe e esposa). Supõe um feminismo universal e acaba justificando a discriminação das mulheres em função da essência feminina. Numa perspectiva social, as diferenças sexuais provêm da socialização e da cultura. Sob esta ótica, a superação da ordem e das leis patriarcais eliminaria as diferenças sexuais.

O objetivo deste trabalho é mostrar as conquistas das mulheres no mercado de trabalho no setor educacional. Na evolução das sociedades as mulheres não tiveram seu espaço realmente reconhecido mesmo ocupando funções de destaque, sofreram vários tipos de preconceito, na Antiguidade eram reservadas apenas para serem boas donas de casa, boas esposas e gerarem fi- lhos fortes.

$\mathrm{Na}$ idade Média eram acusadas de bruxaria, se submetendo às regras do sexo masculino. Este estudo propõe-se a evidenciar desigualdades, lutas e conquistas das mulheres no espaço social, demonstrando a capacidade de executar diversas funções, não se enquadrando ao estigma de sexo frágil muitas vezes citado e seguido na cena social, demonstrando que merecem o respeito e dignidade de participar e de ocupar lugares de destaque na sociedade, com liberdade de mostrar independência e aniquilar qualquer forma de submissão ao qual forem impostas. Sendo visível estabelecer as mudanças nas relações de gênero, construindo um olhar de igualdade nas relações entre homem e mulher.

Para Menuci (2003, p. 376). Lutar contra uma bagagem

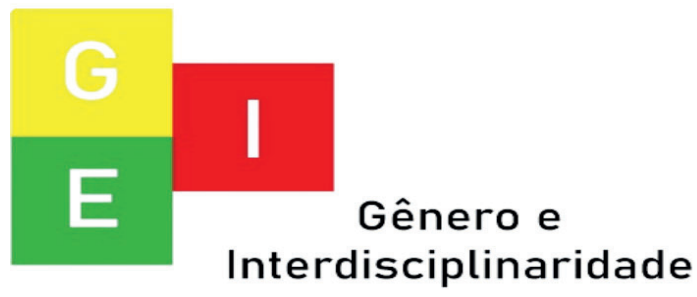


Vol. 02 - n 03 - ano 2021

Editora Acadêmica Periodicojs

histórico-cultural de longas datas dominada essencialmente por homens é uma tarefa árdua, cabe sempre a mulheres fortes o desejo de igualdade entre os gêneros. Historicamente a imposição de serem inferiores aos homens nunca foi aceita pelas mulheres, entretanto as leis e regras estabelecidas na sociedade controlada puramente por homens determinavam as normas e regras sociais.

A importância deste trabalho é demonstrada por sua abordagem antropológica da trajetória feminina no decorrer do tempo, destacando a dominação masculina, da face machista da sociedade, recheada de preconceitos, regras e leis que proíbem e inibem a participação feminina em setores diversos da sociedade. $\mathrm{O}$ aspecto norteador da abordagem temática destaca a igualdade de direitos entre mulheres e homens.
A metodologia realiza-

da de revisão bibliográfica utiliza textos referenciais na abordagem do estudo de movimentos feministas. Utilizando fontes secundárias através de pesquisas em fontes primárias em portais de periódicos em meio físico e digital. Para construção do foi utilizada a técnica de documentação indireta caracterizada como social, pois se dá pela observação do ser humano, na interpretação das informações do mundo onde o objetivo fundamental é descobrir respostas para problemas mediante o emprego de procedimentos científicos. (GIL, 2008. p.45)

Quando se analisa o atual cenário da participação feminina na sociedade se evidencia avanços conquistados, mais evidenciado nas últimas décadas. Os movimentos feministas como grupos organizados, sur-

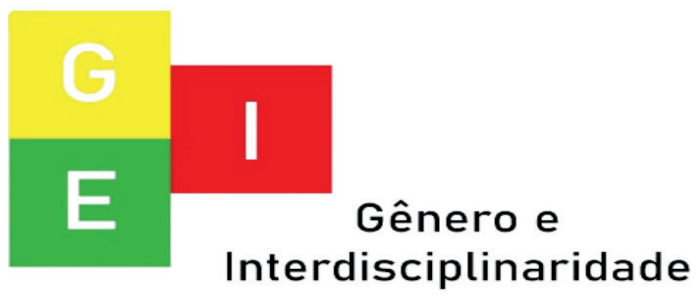


Vol. 02 - n 03 - ano 2021

Editora Acadêmica Periodicojs

giram no Continente Europeu tendo como objetivo confrontar a particular situação de subordinação das mulheres pelos homens (GUIMARÃES，2005). Subordinação enraizada culturalmente em diversas sociedades, que vê a mulher como um ser inferior ao homem, onde o mesmo pode decidir inclusive sobre a vida e a morte.

Bairros (1995, p.462) Reflete o feminismo como "instrumento teórico que permite dar conta da construção de gênero como fonte de poder e de hierarquia que impacta mais negativamente sobre as mulheres podem ser analisadas criticamente". Pensamento conservador e retrogrado dos homens que veem no avanço feminismo uma perca de seu espaço na sociedade.

Lauretis (1994, p.69). Demonstra como são assumidas concepções de gênero que são socialmente aceitas. No mundo do trabalho, a mulher era reservada às tarefas domésticas e não remuneradas. Na Europa do século XIX, com a introdução da mecanização da produção, como característica da Revolução Industrial o trabalhador, que detinha um controle quase absoluto do processo produtivo manufatureiro, viu uma exteriorização do controle do trabalho, concomitantemente, a indústria capitalista abriu as portas para as mulheres e crianças, que se juntaram aos homens no processo produtivo. Segundo (Marx, 1985 apud Daniel, 2011 p.325), “A mecanização da produção foi fundamental para incorporação do trabalho das mulheres e crianças nas fábricas".

As lutas por direitos das mulheres ocorreram nos Estados Unidos e na Europa no final do século XIX. É possível separar

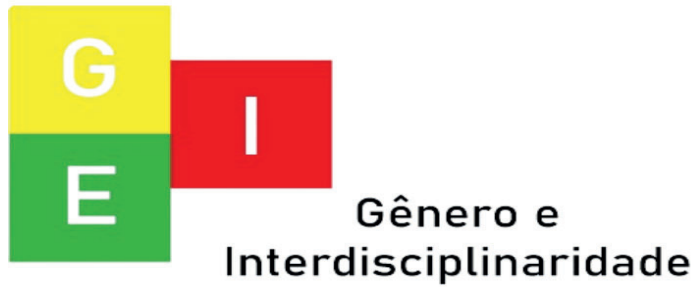


ISSN: 2675-7451

Vol. 02 - n 03 - ano 2021

Editora Acadêmica Periodicojs

em duas vias de lutas e conquistas, a primeira se preocupou com a questão dos direitos civis e o sufrágio universal, a discriminação era tão grande que as mulheres não podiam opinar em questões políticas se não por seus maridos. A segunda as lutas eram para poderem trabalhar fora do lar e terem o direito de estudar, terem um conhecimento melhor. O movimento feminista sofreu muita pressão por parte dos homens que visava à manutenção do estatus quo.

Em Pernambuco durante o governo do então presidente Getúlio Vargas os movimentos feministas emergiram. Esses movimentos feministas eram compostos por mulheres influenciadas por movimentos, como a Federação Brasileira pelo Progresso Feminino tendo o propósito de alcançar igualdade civil e direito social.

\section{A DESIGUALDADE ENTRE HOMENS E MULHERES NO BRASIL}

No Brasil a exploração com a mulher já era realizada antes mesmo da chegada dos portugueses, não há relatos de nenhuma mulher indígena ter assumido uma função de comando nas tribos indígenas cabendo-lhes os afazeres domésticos: como cuidar das crianças, colher, preparar os alimentos, entre outras atividades domésticas.

Os nativos que habitavam o território brasileiro (índios) eram divididos em vários grupos linguísticos em culturas também diversas, com seus hábitos e costumes diferentes, cada tribo se organizavam de uma maneira peculiar, iniciando pela organização familiar, o casamento diferente do modelo ocidental

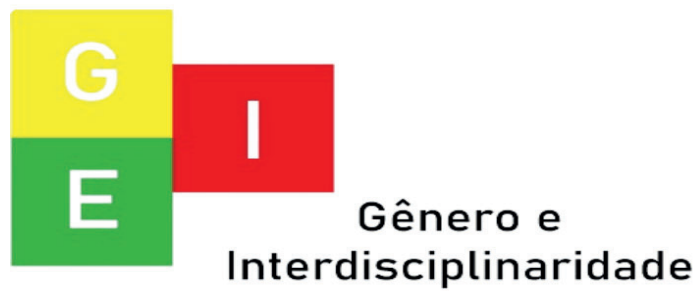


(monogâmico), poderia ser poligâmico ou poliândrico em que as mulheres poderiam dois ou mais parceiros. A esposa indígena não era vista como uma propriedade pelo seu marido índio, mas vista como uma companheira com a qual dividia as tarefas ao contrário do casamento convencional onde na época a mulher era vista por seu marido como uma propriedade adquirida através do matrimônio.

Os colonos utilizavam mulheres índias como reprodutoras, era comum um colono ter duas ou mais índias como suas concubinas, com a chegada do padre jesuíta Manuel da Nóbrega em 1549, ele escreveu ao rei de Portugal que mandassem mulheres, órfãs ou até mesmo meretrizes para serem esposas dos colonos, os jesuítas não aceitavam o estilo de vida dos colonos portugueses com as nativas, para eles estavam agredindo as leis do catolicismo.

"Os primeiros portugueses que para cá vieram eram homens. Poucas mulheres realizavam a penosa e longa travessia do atlântico logo era comum aos colonos manterem concubinas entres as escravas índias". (TELLES, 1993, p.17 e18). A exploração da mulher índia era demasiadamente degradante, além de ser vista como uma selvagem pelo europeu era vista também com um objeto sexual.

$\mathrm{Na}$ visão dos jesuítas a miscigenação deixava de certo modo uma igualdade entre brancos e índios que seria não muito agradável para seus objetivos. Até o século XVIII, mantinha o controle sobre a educação colonial, catequizando índios e colonos, em relação aos índios os jesuítas além da catequização faziam com que trabalhassem em

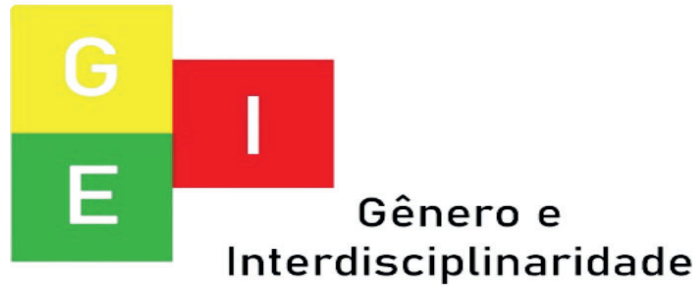


ISSN: 2675-7451

Vol. 02 - n 03 - ano 2021

Editora Acadêmica Periodicojs

suas comunidades religiosas.

Nos engenhos ou fazen-

Com a vinda dos escra-

vos da África para o Brasil boa

parte mulheres, vinha grávida ou

com seus filhos ainda de colo, a

escravidão não respeitava a gra-

videz nem tão pouco as crian-

ças de colo, era costume, muitas

mulheres se jogarem ao alto mar

com suas crianças, morrer para

elas era sinônimo de salvação e

libertação.

Após chegarem aos por-

tos brasileiros, os escravos eram

expostos e geralmente leiloados

em armazéns geralmente as mu-

lheres escravas eram vendidas

de acordo com seus dotes físicos

com a função de serem ventres

geradores de mão de obra para o

trabalho escravo, e também satis-

fazer o desejo sexual dos brancos,

depois da venda iam trabalhar no

campo, fazendas e engenhos ou

ficavam nas cidades, geralmente

como escravas de ganho.

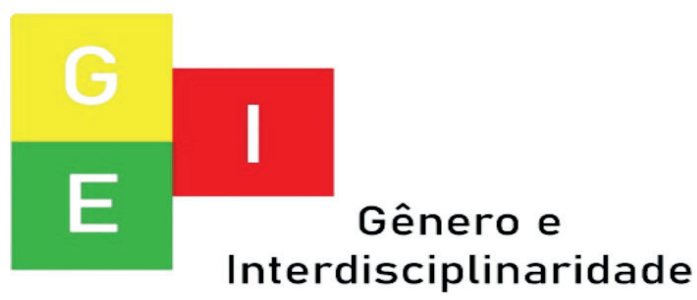

ranjados determinados por eles.

Depois de casada era submetida ao marido e teria que ser uma excelente dona de casa geradora de filhos, preferencialmente homens futuros herdeiros administradores dos bens da família.

Mesmo com tanta violência sexual, moral e física sur- 
giram mulheres guerreiras que lutaram pelo seu espaço na sociedade e contra as injustiças de uma sociedade dominada por homens brancos. Essas mulheres tiveram um papel de destaque, entre elas podem-se destacar segundo Astrid Fontenelle (2019) e Maitê Proença (2020) as mulheres abaixo:

- Paraguaçu, filha de um cacique Tupinambá em 1510 na Bahia salvou o naufrago Diogo Álvares Correia, chamado pelos índios de Caramuru;

- Brites de Albuquerque, esposa do primeiro governador de Pernambuco Duarte Coelho que assumiu o comando da capitania, tornando-se uma das mais ilustres brasileiras, em seu governo, manteve a ordem e a paz da Capitania de Pernambuco, combatendo as insurreições indígenas, legislando e controlando os assuntos dos colonos e cons- truindo e urbanizando núcleos, como Olinda, onde faleceu, provavelmente entre junho e outubro de 1584;

- Maria Margarida de Castro e Albuquerque nasceu em Olinda viveu no século XVII, Senhora de Basto e Condessa de Vimioso, filha única de D. Joana de Castro e do $4^{\circ}$ donatário da capitania de Pernambuco D. Duarte de Albuquerque Coelho, assumiu o governo da capitania de Pernambuco de 1658 a 1689, com bastante firmeza, não levando em considerações o preconceito de só homens governarem as capitanias.

- Aqualtune foi capturada na África e vendia como escrava em 1665, ao desembarcar no Recife e que teria tentado correr para o mar, uma tentativa desesperada para voltar à sua terra natal. Foi então levada para uma fazenda em

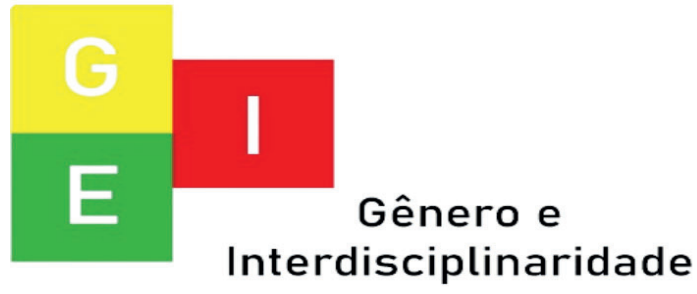


ISSN: 2675-7451

Vol. 02 - n 03 - ano 2021

Editora Acadêmica Periodicojs

Porto Calvo, no sul da Capitania

de Pernambuco (atual estado de

Alagoas). A fazenda onde ficara era especializada em gado e os senhores logos perceberam sua proximidade com outros escravos, por isso deixaram-na nas mãos dos piores homens do lugar.

- Dandara foi uma escrava negra que viveu no Quilombo de Palmares, não se sabe ao certo se ela nasceu no Brasil ou na África, ela foi uma guerreira que ao lado de seu marido Zumbi, líder de Palmares lutou e defendeu o Quilombo contra os brancos que queriam escravizá-los. Em 6 de fevereiro de 1694, quando foi presa. Jogou-se de uma pedreira direto para um abismo. Preferiu a morte a voltar a ser escrava.

A CONQUISTA PELO ESPAÇO DA MULHER NA SOCIE-

\section{DADE PERNAMBUCANA}

A história das mulheres pernambucanas é forjada por lutas contra a desigualdade entre os gêneros, o feminismo é uma filosofia global que considera a existência de uma opressão exclusiva a todas as mulheres.

Segundo Teles (1993, p.11) “A opressão se manifesta tanto no nível das estruturas como das superestruturas (ideologia, cultura e política)”. Assume formas diversas conforme as classes e camadas sociais, nos diferentes grupos étnicos e culturas.

A mulher pernambucana nunca se conteve com a situação a qual o homem autoritário a impusera, muito se conformava com esta condição, mas em todas as épocas surgiram mulheres destemidas a lutarem pelo seu espaço na sociedade.

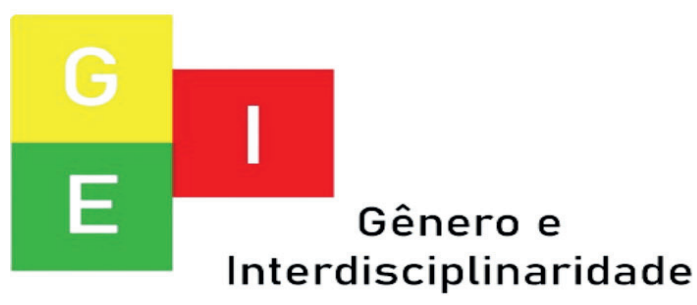


Vol. 02 - n 03 - ano 2021

Editora Acadêmica Periodicojs

Mesmo após abolição do pela crescente manifestação da escravidão, proclamação da feminista, iniciada nos Estados república e o início de um novo Unidos e Europa e em seguida século não trouxeram mudanças nos países da América Latina sociais para as mulheres. As conquistas vieram de forma lenta e gradual.

Segundo (Barbosa,

Tivemos a primeira deputada estadual eleita em 1945, com o fim do Estado Novo. Adalgisa Rodrigues Cavalcanti, eleita Deputada Estadual pelo partido $\mathrm{PCB}$, natural da cidade de Glicério, viveu parte de sua infância na cidade de Arcoverde se mudando para recife com 16 anos, trabalhou como empregada doméstica e vendedora posteriormente participaram da ALN e em outras atividades políticas, sendo presa por defender seus ideais, se engajou aos primeiros movimentos feministas até fazer parte do $\mathrm{PCB}$, onde foi eleita a primeira deputada de Pernambuco.

$\mathrm{O}$ século $\mathrm{XX}$ foi marcachegando ao Brasil, posteriormente em Pernambuco. 2015 p.01) "Os movimentos feministas atuantes em Recife emergiram durante o governo de Getúlio Vargas, o mesmo foi responsável por conceder o direito do voto às mulheres, por meio do decreto-lei em 1932 e fidelizá-lo na constituição de 1934”'. Em 10 de novembro de 1931 iniciou-se a solenidade da posse da primeira diretoria efetiva da Federação pelo Progresso Feminino, no salão nobre do Club Internacional, Edwiges de Sá Pereira.

Edwiges assume características feministas oficialmente a partir de 1931, com a criação da Federação Pernambucana pelo Progresso Feminino. De acordo

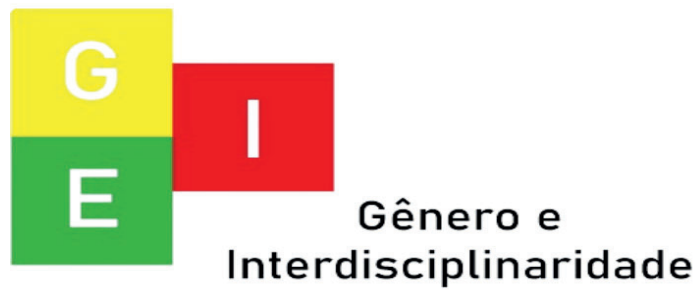


ISSN: 2675-7451

Vol. 02 - n 03 - ano 2021

Editora Acadêmica Periodicojs

com (Nascimento, 1982, apud Barbosa 2015, p 04). " Podemos ainda ressaltar a presença de Edwiges em outros periódicos, como a Revista da Academia Pernambucana de Letras, Azul e Ouro, o Botão do Lyrio, Gazeta Literária, O Prelio, A Limalha, A Nota, A Gazeta, O Ratazana, Revista do Instituto de Sociedade e Letras de Pernambuco e Vida Feminina".

Ainda de acordo com (Barbosa, 2015, p.04). As mulheres líderes em Pernambuco criaram organizações de massas como, Comitês de Bairro, Clubes de Mães, Juventude, e outras organizações. Para Adalgisa, não houve uma líder, havia mulheres que ficavam à frente, mas de certa forma ela pensava que "líderes quem faz é o povo, ele é quem cria os seus líderes".

$\mathrm{O}$ ingresso das mulheres nas escolas de primeiras le- tras, no século passado, marca o despontar do feminino para vida pública, como também, o início de uma trajetória de lutas e conquistas, desse gênero, na sociedade brasileira. A feminização do trabalho docente acontece em concomitância com a expansão mundial dos sistemas de ensino, por sua vez, como um requisito do próprio desenvolvimento do capitalismo.

Outro movimento feminista estampou notícias na cidade do Recife, a Cruzada Feminista Brasileira e sua líder Martha de Hollanda propuseram um movimento feminista, com características sufragistas, assim como a Federação Pernambucana.

Inicialmente, o ensino era uma esfera de atividade masculina, mesmo porque, até o início do século XX, um conjunto de medidas legais restringia o acesso das mulheres às escolas,

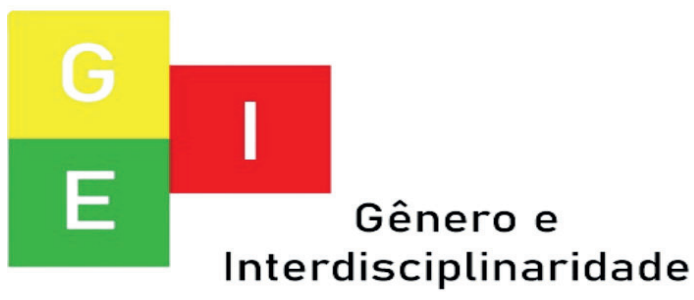


Vol. 02 - n 03 - ano 2021

Editora Acadêmica Periodicojs

e, portanto, à habilitação profissional. Apenas em 1827, surgiu a primeira regulamentação que permitia às mulheres frequentarem o ensino elementar.

Segundo (Lopes, 2013

p.68). " Como em muitas partes do país e do mundo, as mulheres pernambucanas, em especial as recifenses, que perseguiam seus propósitos, eram alvo de críticas ao pretenderem continuar seus estudos além do Magistério. ', As mulheres só tiveram acesso a escola em Pernambuco a partir de 1875, na escola Normal Pinto Júnior, ao terminar o antigo ensino básico ficavam sem estudar, ingressar no ensino superior era privilégio do sexo masculino, em 1944 a primeira mulher colou grau no ensino superior na Escola Superior de Agricultura de Pernambuco, no curso de agronomia. A partir daí outros cursos foram aceitando as mulheres em suas salas de aulas, inserindo a mulher na educação superior.

No mercado de trabalho foi outra grande dificuldade das mulheres conseguirem seu espaço, ao se tornarem professoras tinha salários baixíssimos, eram vistas pela sociedade como uma coisa natural já que não dependiam de sua renda para sobreviver, mas apenas um complemento.

A absorção das mulheres pelo mercado de trabalho, nessa época, aconteceu por dois caminhos. O primeiro foi através da indústria têxtil, que começou a despontar no quadro do desenvolvimento do capitalismo, e o segundo, através da educação. Na educação só era permitida ser professora do primário a partir da década de 70 as mulheres começaram a ter mais visibilidade como professoras universitárias. No mercado de trabalho em ou-

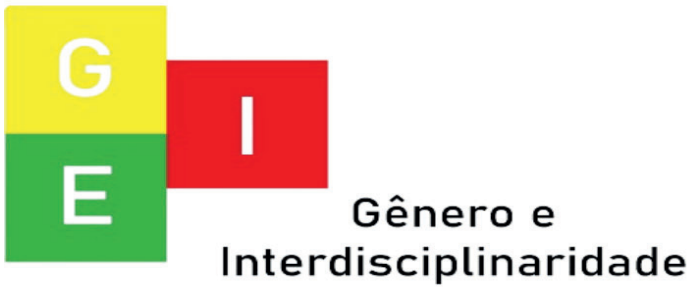


ISSN: 2675-7451

Vol. 02 - n 03 - ano 2021

Editora Acadêmica Periodicojs

tras profissões exerciam as mesmas funções dos e recebiam menos.

O desenvolvimento das capacidades intelectuais femininas atreladas ao exercício de uma profissão ou pratica social útil à sociedade, era o ideal de mulher construído nos movimentos feministas, o desejo primordial é se sentir valorizada, capacitada a se engajar em qualquer espaço que queira na sociedade, pois o lugar da mulher é onde ela quer estar. A partir da década de 90 houve mais engajamento da mulher no mercado de trabalho e no setor educacional. Porém muito caminho tem a percorrer.

A questão da desigualdade entre os seres humanos, homens e mulheres é parte da história da humanidade. Estão presentes nos mais diversos discursos; filosófico, religioso, biológico/científico, psicológico, antropológico e social. Mas é na modernidade que esse tema ganha maior relevância como objeto de análise.

\section{CONCLUSÃO}

A desigualdade entre homens e mulheres se faz presente na sociedade desde o início dos tempos. Embora algumas mudanças tenham ocorrido, ainda permanecem as desigualdades entre ambos os gêneros, dado que conceitos e comportamentos patriarcais que inferiorizam a condição da mulher continuam sendo percebidos em instituições de toda ordem, como na política, nas ciências, nos comportamentos sociais, na cultura e em vários outros aspectos. Nesse sentido, o presente estudo se propôs a analisar como se originou essas desigualdades entre o homem e a mulher, na qual este homem

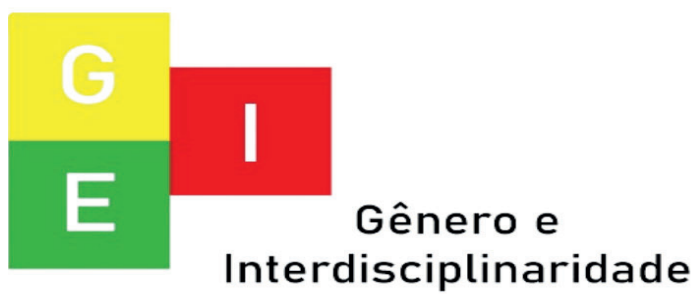


ISSN: 2675-7451

Vol. 02 - n 03 - ano 2021

Editora Acadêmica Periodicojs

dominou o espaço em sua volta tornando a mulher um ser meramente coadjuvante na sociedade, este estudo ainda traz uma abordagem das lutas de mulheres que não se deixaram por vencidas em suas casas, saindo da penumbra da sociedade puramente machista, conseguiram por muitas vezes mostrar que são persistentes naquilo que querem e acreditam lutar pelo seu espaço em mundo dominado pelos homens.

Em diversas sociedades de épocas diferentes houve mulheres que lutaram pelo seu espaço, com o objetivo de mostrar que são capazes de serem iguais e até serem melhor do que os homens em vários aspectos sociais.

A indagação dos conceitos machistas continua existindo na sociedade, é o principal problema sob qual se debruça este trabalho. Outra discussão apontada aqui e merece ser tratada, é o fato das mulheres recorrerem aos seus direitos, ocuparem espaços na sociedade e ainda assim o machismo prevalece forte.

As mulheres, por histórica e culturalmente serem relegadas ao espaço privado e responsabilizadas pelo trabalho doméstico, que não é considerado produtivo e, portanto, não remunera, foram durante séculos excluídos das principais possibilidades de acesso à renda e ao mercado de trabalho e a educação.

\section{REFERÊNCIAS}

ALBERNAZ, Lady Selma Ferreira; Feminismo Até Certo Ponto: Representação do feminismo no contexto das praticas profissionais e de gênero. Dissertação apresentada na UFPE. Recife. PE. 1996.

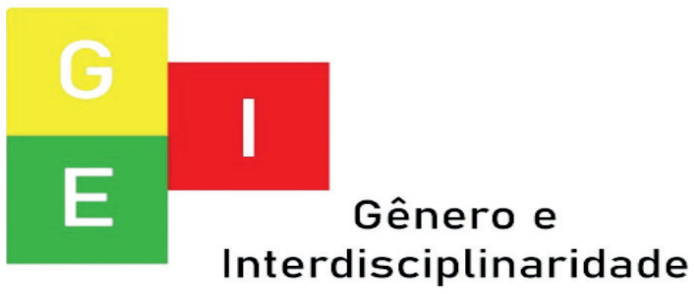


Vol. 02 - n 03 - ano 2021

Editora Acadêmica Periodicojs

ARANHA, Ma Lúcia de Arruda. QUIVO_ArtigocompletoIzabel-

História da Educação na Grécia leAnpuh2015>. Acesso em: 28

Antiga. São Paulo: Editora Mo- mar.2021.

derna, 2006.

BAIRROS, Luiza. Nossos femi-

ARRUDA, Ângela. Feminismo, nismos revisitados. Estudos fe-

Gênero e Representações Soministas, v. 3, n. 2, p. 458- 463, ciais. Rio de Janeiro, RJ. Editora 1995.

UFRJ. V.8. $n^{0}$ 1/2.2020.

BELO, Tais Pagoto. Mulheres da AQUALTUNE. a princesa escraAntiguidade: apenas um espelho. vizada no Brasil que lutou pela Disponível em https://docplayer. liberdade de seu povo. Astrid com.br/53364968-Mulheres-daFontenelle. CanalDaAstrid, 2019. -antiguidade-apenas-um-espeYoutube. Acesso em 24 fev 2021. 1ho.htm12017. Acesso em 24 de Disponivel em: https://www.youAbr. de 2021.

tube.com/watch? $\mathrm{v}=9 \mathrm{EwWIRU1-}$ Mg8.

BONNETI, Alinne. SOUZA, Ângela Maria Freire de Lima. BARBOSA, Isabelle Lúcia de Gênero, Mulheres e Feminismo. Oliveira; OS Movimentos FemiSalvador, BA. Editora UFBA. nistas Pernambucanos e Debate 2011.

em Torno do Divorcio (19261937). 2015.Disponível em: BRITES DE ALBUQUERQUE $<$ http.//www.anpuh.org/resour| MULHER DE FIBRA. Maitê ces/anais 39/1434419764_ARProênça. Canal da Maitê, 2020.

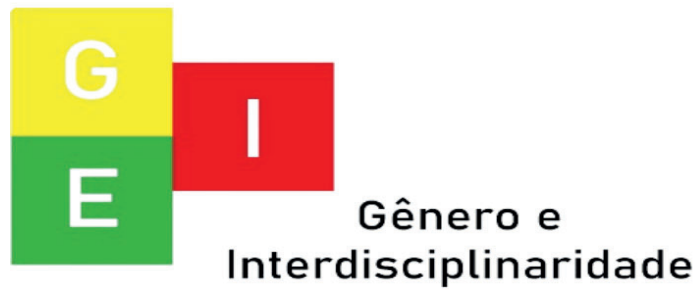


Youtube. Acesso em 24 fev 2021.

Disponivel em: https://www.youtube.com/watch?v=hTU3noyBxjw.

\section{CATARINA PARAGUAÇU:}

uma indígena Tupinambá, mãe das mães brasileiras | MULHE-

RES ADMIRÁVEIS. Astrid Fontenelle. CanalDaAstrid, 2019. Youtube. Acesso em 24 fev 2021. Disponivel em: https://www.youtube.com/watch?v=X_Sl-0ZR$1 \mathrm{pM}$.

DANDARA | Mulheres admiráveis \#04. Astrid Fontenelle. CanalDaAstrid, 2019. Youtube. Acesso em 24 fev 2021. Disponivel em: https://www.youtube. com $/$ watch? $\mathrm{v}=\mathrm{tUhBeV} 8 \mathrm{zlbA}$

DANIEL, Camila. O trabalho e a questão de gênero: a participação de mulheres na dinâmica do trabalho. Disponível em <.http:// osocialemquestao.ser.pucrio.br/ media/17_OSQ_25_26_Daniel. pdf.> Acesso em 29 de mar.de 2021.

GIL, A. C. Como elaborar projetos de pesquisa. São Paulo: Atlas, 2008 .

GUERRA E LIBERTAÇÃO e libertação: a história de Dandara dos Palmares: uma indígena Tupinambá, mãe das mães brasileiras | MULHERES ADMIRÁVEIS. Astrid Fontenelle. CanalDaAstrid, 2019. Youtube. Acesso em 24 fev 2021. Disponivel em: https://www.youtube.com/wat$\mathrm{ch} ? \mathrm{v}=\mathrm{EOnUvmRnMw8.}$

GUIMARÃES，Selva. Didática e prática de ensino de história: experiências, reflexões e aprendizados. 13 Ed. campinas, SP. Papirus. 1993.

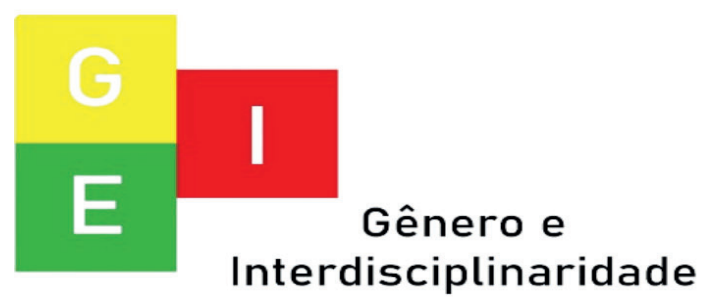


Vol. 02 - n 03 - ano 2021

Editora Acadêmica Periodicojs

HAAG, Carlos. ALMEIDA, Co-

lagens Hélio De. A mulher num

mundo de homens Estudos do corpo feminino colocam em xeque velhas noções de gênero.

Disponível $\quad \mathrm{em}<\mathrm{https}$ ://revistapesquisa.fapesp.br/wp-content/ uploads/2005/11/086-089-antropologia.pdf $>$. Acesso em 28 de Nov. de 2021.

GEVEHR, Luciano Daniel; SOUZA, Vera Lúcia. As Mulheres e a Igreja Na Idade Média: misoginia, demonização e caça as bruxas. 2014.Disponível <... http://ieduc.org.br/ojs/index.php/ licenciaeacturas/article/viewFile/38/34...> Acesso em 21 de Nov. de 2020.

La Ville C., Dionne J. A construção do saber - manual de metodologia da pesquisa em ciências humanas. Belo Horizonte, Editora UFMG, 1999.
LAURETIS, Tereza. Tecnologia de Gênero. Disponível $<<$. http:// marcoaureliosc.com.br/cineatro pó/lauretis.pdf $>$. Acesso em 23 de jan. de 2021.

LOPES, Conceição. MULHERES PIONEIRAS, MULHERES DE RENOME: AS ENGENHEIRAS AGRÔNOMAS PERNAMBUCANAS DA PRIMEIRA METADE DO SÉCULO XX (Década de 40). Disponível em; $<$ httpfile://C:/Users//Downloads $/ 82$-Texto $\% 20$ do $\% 20$ Artigo-334-2-10-20130830\%20(1).> Anais da Academia Pernambucana de Ciência Agronômica, Recife, vol. 4, p.65-82, 2007.

MENUCI, Julia. História das mulheres: a dicotomia pública privada e a desigualdade salarial feminina no mercado de trabalho do Estado do Rio Grande

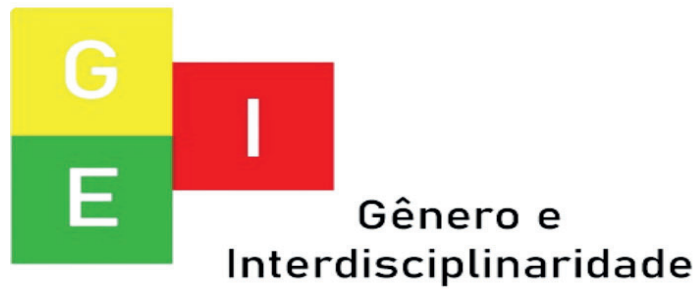


Vol. 02 - n 03 - ano 2021

Editora Acadêmica Periodicojs

do Sul. Disponível em <https.// S0102-71822006000100007.

periódicos.utfpr.edu. br/cgt. v.13 Acesso em: 28 mar 2021.

m.42.2020>. Acesso em $20 \mathrm{de}$ fev. de 2021.

PINSKY, Carla Bassanezi, PE-

DRO, Joana Maria. Nova Histó-

MONTEIRO, Kimberly Farias; ria das Mulheres no Brasil. São GRUBBA, Leilane Serratine. Paulo. SP. Editora Contexto. 2012 A luta das mulheres pelo espaço público na primeira onda do REED, Evelyn. Sexo contra sexo feminismo: de suffragettes às ou classe contra classe. São Pausufragistas. Disponível em: $<$ htlo.SP. $2^{\text {a }}$ Edição. Editora Institutps://doi.org/10.25246/direitoedeto José Luís e Rosa Sudermann, senvolvimento.v8i2.563>publica2008.

do em 07 de Dezembro de 2017. Acesso em 27 de Nov. de 2020

PINTO, Célia Regina Jardim. Feminismo, História e Poder. MORIN, Edgar. Cultura e BarbáCuritiba, PR. Revista, Sociol. rie Européias. Rio de Janeiro, RJ Polit.V.18. no 36 p. 15-23. Junho Editora Bertrand Brasil $1^{\text {a }}$ Edi2010. ção. 2005.

TELES, Maria Amélia de AlmeiNARVAS, Martha Giudice. KOLda; Breve História do Feminismo LER, Sílvia Helena. Famílias e no Brasil. São Paulo.SP Editora, patriarcado: da prescrição normaBrasiliense. 1993 tiva à subversão criativa. Disponível em: https://doi.org/10.1590/ TÔRRES, Moisés Romanazzi.

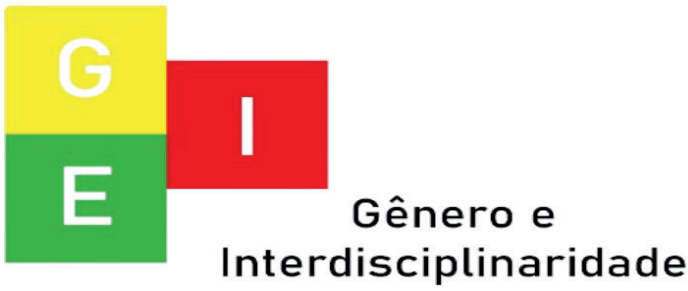


ISSN: 2675-7451

Vol. 02 - n 03 - ano 2021

Editora Acadêmica Periodicojs

Considerações sobre a condição

da mulher na Grécia Clássica

(sécs. V e IV a.C.).Disponível em

file://C:/Users/MOBILE/Down-

loads/Dialnet-Consideracoes-

SobreACondicaoDaMulherNa-

GreciaClassic-2226874\%20(2).

pdf2001. Acesso em 22 de Set.

2020.

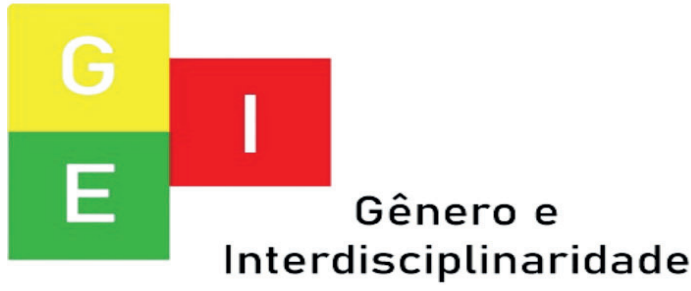

